\title{
INFLUENCIA DE LA PRESENCIA DE BORRAS DURANTE EL TIEMPO DE REPOSO DEL VINO BASE SOBRE ALGUNOS COMPUESTOS VOLÁTILES DEL PISCO PERUANO DE UVA ITALIA
}

\author{
Yasser Hidalgo ${ }^{* a}$, Beatriz Hatta ${ }^{\mathrm{a}}$, Juan Carlos Palma ${ }^{\mathrm{b}}$
}

\begin{abstract}
RESUMEN
Se investigó la influencia de la presencia de borras durante el reposo del vino base sobre algunos compuestos volátiles en el pisco, como: ácido acético, alcoholes superiores, ésteres y acetaldehído. Dos fracciones de vino base seco (con y sin borras) se almacenaron por cinco intervalos de tiempo: 0, 7, 20, 60, 150 días; y destiladas después. Los resultados indicaron que los piscos de vinos base con mayores tiempos de reposo presentan mayores contenidos de ácido acético (con borras: desde $0,15 \mathrm{~g} / \mathrm{L}$ con 0 días de reposo hasta $0,30 \mathrm{~g} / \mathrm{L}$ con 60 días de reposo y $0,69 \mathrm{~g} / \mathrm{L}$ con 150 días de reposo; sin borras: desde $0,14 \mathrm{~g} / \mathrm{L}$ con 0 días de reposo hasta $0,26 \mathrm{~g} / \mathrm{L}$ con 150 días de reposo), propanol (con borras: desde 72,15 mg/100 mL A.A.c con 0 días de reposo hasta 105,34 mg/100 mL A.A. con 150 días de reposo), acetato de etilo (con borras: desde 22,00 mg/100 mL A.A. con 0 días de reposo hasta 43,10 mg/100 mL A.A. con 150 días de reposo) y acetato de iso-amilo (con borras: desde $0,00 \mathrm{mg} / 100 \mathrm{~mL}$ A.A. con 0 días de reposo hasta $10,57 \mathrm{mg} / 100 \mathrm{~mL}$ A.A. con 150 días de reposo); y menores contenidos de acetaldehído (con borras: desde 22,71 mg/100 mL A.A. con 0 días de reposo hasta 4,29 $\mathrm{mg} / 100 \mathrm{~mL}$ A.A. con 60 días de reposo y 3,30 mg/100 mL A.A. con 150 días de reposo; sin borras: desde 16,98 mg/100 mL A.A. con 0 días de reposo hasta 4,30 mg/100 mL A.A. con 150 días de reposo). Los piscos destilados de vinos base con borras presentan mayores cantidades de acetato de etilo (22,00 vs. $16,61 \mathrm{mg} / 100 \mathrm{~mL}$ A.A.) y acetaldehído (22,71 vs. $16,98 \mathrm{mg} / 100 \mathrm{~mL}$ A.A.), que sus destilados de vinos base sin borras, con 0 días de reposo.
\end{abstract}

Palabras clave: Destilados, pisco, borras, tiempo de reposo, compuestos volátiles.

\section{INFLUENCE OF LEES PRESENCE DURING THE RESTING TIME OF BASE WINE IN SOME VOLATILE COMPOUNDS OF PERUVIAN ITALIA GRAPE PISCO}

\footnotetext{
a. Facultad de Industrias Alimentarias, Universidad Nacional Agraria La Molina. Av. La Universidad s/n, Lima 12, Perú.

*yasser_hds@yahoo.com

${ }^{\mathrm{b}}$ Facultad de Ciencias - Dpto. de Química, Universidad Nacional Agraria La Molina, Av. La Molina s/n, La Molina, Lima 12, Perú.

${ }^{c}$ A.A.: alcohol anhidro/anhydrous alcohol.
} 


\begin{abstract}
The influence of lees presence during the resting time of base wines in some volatile compounds in Pisco obtained therefrom were studied, such as: acetic acid, higher alcohols, esters and acetaldehyde. Two dry base wine fractions (with and without lees) were stored for five time intervals: $0,7,20,60,150$ days, and distilled afterwards.

The results indicated that piscos obtained from base wines with longer resting time show higher acetic acid contents (with lees: from $0.15 \mathrm{~g} / \mathrm{L}$ with 0 resting days to $0.30 \mathrm{~g} / \mathrm{L}$ with 60 resting days and $0.69 \mathrm{~g} / \mathrm{L}$ with 150 resting days; without lees: from $0.14 \mathrm{~g} / \mathrm{L}$ with 0 resting days to $0.26 \mathrm{~g} / \mathrm{L}$ with 150 resting days), propanol contents (with lees: from $72.15 \mathrm{mg} / 100$ $\mathrm{mL}$ A.A. with 0 resting days to $105.34 \mathrm{mg} / 100 \mathrm{~mL}$ A.A. with 150 resting days), ethyl acetate contents (with lees: from $22.00 \mathrm{mg} / 100 \mathrm{~mL}$ A.A. with 0 resting days to $43.10 \mathrm{mg} / 100 \mathrm{~mL}$ A.A. with 150 resting days) and iso-amyl acetate contents (with lees: from $0.00 \mathrm{mg} / 100$ $\mathrm{mL}$ A.A. with 0 resting days to $10.57 \mathrm{mg} / 100 \mathrm{~mL}$ A.A. with 150 resting days); and lower acetaldehyde contents (with lees: from $22.71 \mathrm{mg} / 100 \mathrm{~mL}$ A.A. with 0 resting days to 4.29 $\mathrm{mg} / 100 \mathrm{~mL}$ A.A. with 60 resting days and $3.30 \mathrm{mg} / 100 \mathrm{~mL}$ A.A. with 150 resting days; without lees: from $16.98 \mathrm{mg} / 100 \mathrm{~mL}$ A.A. with 0 resting days to $4.30 \mathrm{mg} / 100 \mathrm{~mL}$ A.A. with 150 resting days). Piscos coming from base wines with lees show higher ethyl acetate (22.00 vs. $16.61 \mathrm{mg} / 100 \mathrm{~mL}$ A.A.) and acetaldehyde (22.71 vs. $16.98 \mathrm{mg} / 100 \mathrm{~mL}$ A.A.) contents than those coming from base wines without lees, with 0 resting days.
\end{abstract}

Key words: Distillates, Pisco, lees, resting time, volatile compounds.

\title{
INTRODUCCIÓN
}

El pisco es el producto obtenido exclusivamente por destilación de mostos frescos de "uvas pisqueras" recientemente fermentados, utilizando métodos que mantengan los principios tradicionales de calidad; y producido en la costa de los departamentos de Lima, Ica, Arequipa, Moquegua y los Valles de Locuma, Sama y Caplina del departamento de Tacna ${ }^{1}$.

El prensado de las uvas tiene por objetivo extraer la solución acuosa contenida en las bayas, así como ciertos compuestos del hollejo bajo el efecto de la presión. Esta operación se realiza en una prensa, que es, en general, un cilindro en el interior del cual la vendimia es comprimida, sea por el movimiento de uno o dos platos (prensas mecánicas) o por el inflado de una membrana (prensas neumáticas). La presión aplicada debe ser progresiva y alcanzar valores finales bastante elevados pero no demasiado para no romper los raspones, los hollejos y las pepitas ${ }^{2}$.

Desde el punto de vista teórico, 100 gramos de azúcares producen alrededor de 50 gramos de alcohol y 50 gramos de gas carbónico ${ }^{3}$. Además del alcohol etílico, en la fermentación alcohólica se producen a partir del ácido pirúvico otros compuestos, donde destacan el ácido 
acético, ácido butírico, acetona, ácido láctico, acetoína, butanodiol-2,3, ácido fumárico, ácido oxalacético, ácido succínico, ácido propiónico, diacetilo, etc. ${ }^{4}$

La mayoría de los ácidos orgánicos restantes son producidos durante la vía de síntesis de los ácidos grasos a partir de la malonyl-Coenzima $\mathrm{A}^{5}$. Los ésteres se forman por reacciones entre alcoholes y ácidos, bajo la acción de esterasas de las levaduras y directamente por condensación del precursor del ácido acético, el acetil-CoA ${ }^{3}$. La transformación de los aminoácidos de la uva, o los formados por la propia levadura, dan lugar a numerosos alcoholes superiores, que tienen más de 2 átomos de carbono, tales como los alcoholes propílicos, butíricos o amílicos ${ }^{3}$.

En el mosto también están presentes ciertas sustancias volátiles ligadas a la tipicidad aromática de la cepa, las cuales pertenecen esencialmente a dos familias químicas: las pirazinas (características de la familia del Cabernet Sauvignon) y los terpenoles (característicos de los moscateles) ${ }^{5}$. Durante la fermentación, el contenido de nerol y geraniol (terpenoles) decrecen, mientras que el linalol libre casi no varía; en general, se experimenta un descenso de terpenos libres como de ligados, lo que parece indicar que una proporción de estos compuestos sufre algún tipo de degradación ${ }^{6}$.

El inicio de la destilación de los mostos fermentados debe realizarse inmediatamente después de concluida la fermentación ${ }^{1}$. Sin embargo, tal como se acostumbra en la mayoría de bodegas pisqueras, el mosto fermentado se dejar reposar una semana para favorecer la sedimentación y eliminación de las borras (sólidos de mosto y levadura) mediante un trasiego ${ }^{7}$, y en el caso de algunas bodegas industriales, mediante una posterior filtración. Asimismo, estas bodegas industriales, que manejan grandes volúmenes en cuba, se ven en la necesidad de conservar sus mostos ya fermentados durante varias semanas o meses, debido al cuello de botella que se origina en el proceso de destilación.

Durante el reposo, los vinos sufren de manera espontánea una fermentación maloláctica bajo la acción de diferentes bacterias lácticas ${ }^{5}$. Esta consiste básicamente en la descarboxilación del ácido $\mathrm{L}(+)$ málico en el vino a ácido $\mathrm{L}(+)$ láctico, con la liberación de dióxido de carbono 5 . Un gramo de ácido málico tiende a producir 0,67 gramos de ácido láctico y 0,33 gramos de anhídrido carbónico ${ }^{8}$. Se constata también un aumento de los compuestos acetato de etilo, acetales, TDN (o trimetil( $1,1,6)$ dihidronaftaleno), que más allá de cierto nivel, son el origen de defectos importantes en los aguardientes, mientras que diversos acetatos y ciertos ésteres de ácidos grasos, responsables de aromas afrutados o florales, ven cómo su concentración disminuye significativamente ${ }^{5}$.

El trasiego es el proceso de transferir el zumo o el vino de un contenedor a otro, de forma que se vacíe el líquido sobrenadante claro y se deje el sedimento. Puede haber muchos sedimentos en el mosto y en el vino, tales como partículas sólidas de la uva, levaduras y bacterias, cristales de tartrato, sedimento de clarificantes, metales y precipitados proteicos, etc. ${ }^{9}$

La obtención del aguardiente será por destilación directa y discontinua, separando las cabezas y colas para seleccionar únicamente la fracción central del producto llamado cuerpo 
o corazón. Los equipos serán fabricados de cobre o estaño; se puede utilizar pailas de acero inoxidable ${ }^{1}$.

Algunas reacciones químicas tienen lugar en el curso de la destilación ${ }^{10}$ :

- La hidrólisis de diversos constituyentes del vino.

- Formación de acetato de etilo.

- Formación de furfural, durante todo el calentamiento sobre las pentosas.

- Fijación de ácidos grasos y sulfuros por el cobre.

- Formación de glicerol en las partes descendentes del alambique, a partir de las sustancias grasas por reacción sobre el cobre caliente.

La cantidad de borras aportadas al vino en el alambique puede modificar sensiblemente el perfil aromático de los aguardientes obtenidos ${ }^{5}$. Su uso en la destilación proporciona más ésteres de ácidos grasos (octanoato o caprilato de etilo, decanoato a caprato de etilo, dodecanoato o laurato de etilo y ésteres de $\mathrm{C} 14$ a C18), más ácidos grasos y más componentes nitrogenados (aminoácidos) ${ }^{10}$.

Se consideran componentes volátiles y congéneres del pisco, las siguientes sustancias: ésteres, furfural, ácido acético, aldehídos, alcoholes superiores y alcohol metílico1. Estos componentes están influenciados por varios factores durante el proceso de producción, entre los cuales podemos distinguir los siguientes ${ }^{11}$ :

1. Sustancias de aroma primario: generadas a partir de la variedad de la uva.

2. Sustancias de aroma secundario: generadas durante la vinificación y durante el proceso de fermentación.

3. Aromas de sustancias generadas durante el proceso de destilación.

4. Aromas de sustancias generadas durante el proceso de maduración o envejecimiento.

El ojetivo del presente estudio es determinar la influencia de la presencia de borras durante el tiempo de reposo del vino base sobre los contenidos de ácido acético, propanol, acetato de etilo, acetato de iso-amilo y acetaldehído del pisco de uva Italia.

\section{PARTE EXPERIMENTAL}

\section{Materia prima}

Uva de la variedad Italia (Vitis vinifera L. var. Italia), procedente del fundo San Pablo del distrito de Chincha Baja, provincia de Chincha, departamento de Ica.

\section{Análisis fisicoquímicos}

Se determinó los componentes volátiles del pisco: metanol, furfural, acetaldehído, ácido acético, ésteres (acetato de etilo, acetato de isoamilo, formiato de etilo) y alcoholes superiores (propanol, isopropanol, butanol, isobutanol y alcohol iso/teramílico). Se utilizó un cromatógrafo de gases marca Hewlett Packard ${ }^{\circledR}$, modelo GC 6890 con columna capilar 
Agilent, tipo P-FFAP y detector FID. Método cromatográfico y condiciones de trabajo según Norma Técnica Peruana NTP 211.03512.

\section{Análisis estadístico}

Los resultados se procesaron estadísticamente por análisis de varianza (ANOVA) y por medio de la prueba de comparaciones múltiples de Tukey a un nivel de significancia de 5\%, procesados con el programa estadístico Minitab Release 14, para Windows.

\section{Metodología experimental}

Obtención del mosto: los racimos de uva Italia se procesaron en una prensa neumática para extraer el zumo y eliminar la piel y los racimos.

Fermentación: el mosto de uva Italia fue depositado en un tanque de acero inoxidable de 200 L con sistema de agitación y se agregó un pie de cuba con levadura seleccionada (levadura seca activa Saccharomyces cerevisiae Maurivin ${ }^{\mathrm{TM}}$ ). La utilización de levadura seca activa comercial es una práctica común entre las bodegas vitivinícolas como "Bodegas \& Viñedos Tabernero S.A.C.”. Tiene entre sus principales ventajas permitir un comienzo rápido de la fermentación 9 e iniciar la fase exponencial de crecimiento en el menor tiempo posible ${ }^{13}$. El sistema de agitación sólo se utilizó al final de la fermentación con el objetivo de homogenizar la muestra antes de las etapas de filtración y reposo.

Filtración: en esta etapa se introdujo el factor "presencia de borras". Así, concluida la fermentación, una fracción del vino base seco $(990 \mathrm{~g} / \mathrm{L})$ fue despojada de sus borras mediante un filtro de placas.

Reposo: el vino base seco, sin filtrar y filtrado, se sometió en esta etapa, al factor "tiempo de reposo", siendo depositado en botellones de vidrio de 10 litros de capacidad (previamente desinfectados), sin dejar espacio libre de cabeza y cerrándose herméticamente. Los tiempos de reposo de las muestras de vino base fueron: 0, 7, 20, 60 y 150 días.

Trasiego: las muestras de vino base seco sin filtrar, luego de haber concluido el tiempo de reposo respectivo, fueron trasegadas antes de ser destiladas.

Destilación: en un intervalo aproximado de 10 minutos desde la extracción de la muestra, se procedió a destilar aproximadamente $2,5 \mathrm{~L}$ de vino base en un alambique de cobre de $5 \mathrm{~L}$ de capacidad. Se separó al inicio de la destilación la primera fracción de destilado (cabeza) equivalente al $1 \%$ del volumen de vino a destilar y se cortó la misma a una graduación alcohólica de $42^{\circ} \mathrm{G} . \mathrm{L}$ (alc. vol.), aproximadamente. De acuerdo con Domenech6, en el Perú el porcentaje de cabeza eliminado (porcentaje al volumen del vino base a destilar) oscila entre 0,0 y $1,0 \%$. En el presente trabajo se ha considerado $1,0 \%$ por ser el valor más usado en los estudios de investigación de origen nacional. Con respecto a la graduación alcohólica final del pisco, según Hatta ${ }^{10}, 42^{\circ}$ G.L. (alc. vol.) es el grado alcohólico promedio de los piscos comerciales en el Perú. 
Conservación: los destilados se dejaron reposar durante tres meses en botellas de vidrio según lo recomendado por el Reglamento de la Denominación de Origen PISCO1, antes de someterlos a análisis. Luego de concluida esta etapa, los piscos fueron caracterizados determinando sus compuestos volátiles.

\section{Diseño experimental}

Para evaluar los factores "presencia de borras" en el vino base, con sus niveles: con borras y sin borras; y el factor "tiempo de reposo" del vino base, con sus niveles: 0, 7, 20, 60 y 150 días; se utilizó un Diseño Factorial Completamente al Azar (DCA) con tres repeticiones.

\section{RESULTADOS Y DISCUSIÓN}

\section{Ácido acético}

Tal como se observa en la figura 1, el contenido de ácido acético tuvo mayores concentraciones en los piscos provenientes de vinos base con borras con 60 y 150 días de reposo, y en los provenientes de vinos base sin borras con 150 días de reposo.

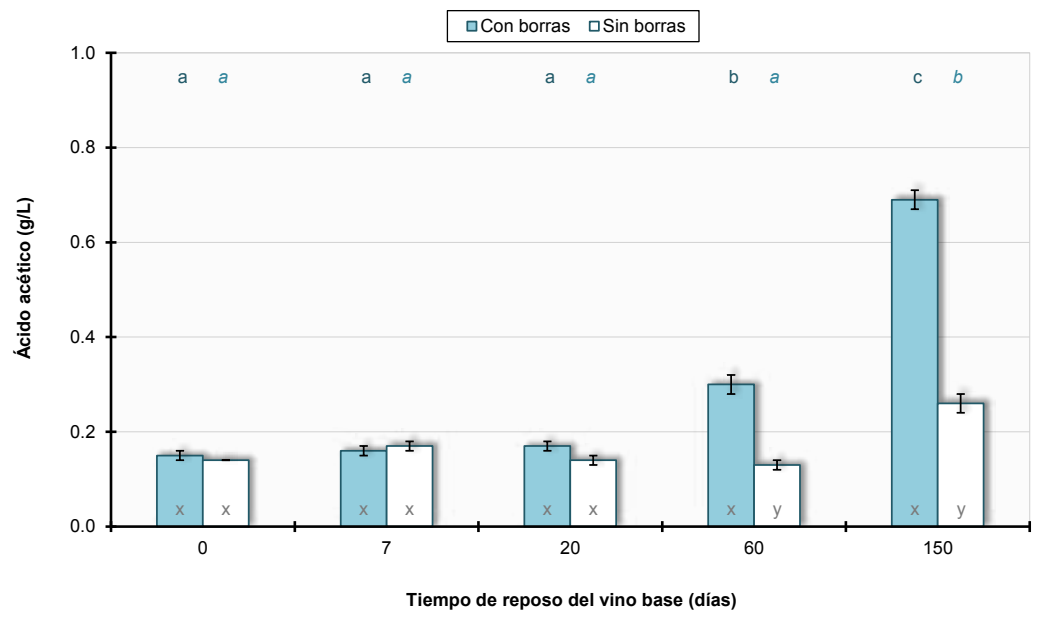

Figura 1. Contenido de ácido acético en los piscos provenientes de vinos base (con y $\sin$ borras) con diferentes tiempos de reposo.

Las figuras 2 y 3 muestran los cromatogramas de dos muestras de piscos provenientes de vinos base con 150 días de reposo. En el primer caso se trata de un vino base con borras mientras que en el segundo de un vino base sin borras. Respecto al ácido acético, se puede observar claramente la diferencia en las alturas de los picos de ambas figuras. En el cromatograma de la figura 2 (con borras), el pico del ácido acético es más alto que en el de la figura 3 (sin borras). Estas mediciones se traducen en los resultados que se muestran en la figura 1, a los 150 días de reposo. 
Una vez que el vino se ha alojado en la cuba bien cerrada y provista de buen sello, el vino estará al abrigo de las alteraciones y podrá esperar a ser destilado sin que sea útil realizar otros tratamientos. Por regla general, durante este reposo, los vinos sufren de manera espontánea una fermentación maloláctica bajo la acción de diferentes bacterias lácticas5. Fueron precisamente estas condiciones las que se crearon en el presente trabajo; llenando hasta el tope con vino base los recipientes utilizados y cerrándolos inmediatamente.

El ataque del ácido cítrico con formación de ácido acético es el responsable del aumento de la acidez volátil que se observa a lo largo de la degradación del ácido málico14. Su degradación comienza al mismo tiempo que la del ácido málico, pero es mucho más lenta, quedando a menudo ácido cítrico al final de la fermentación maloláctica15. Esto explicaría el aumento en la concentración de ácido acético en los piscos provenientes de vinos base con borras.

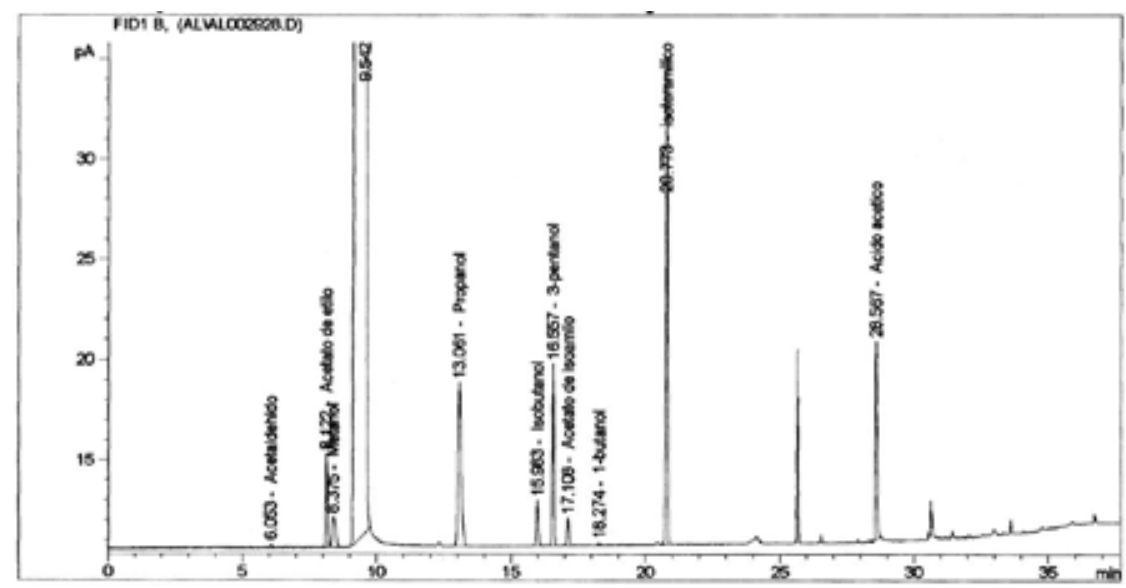

Figura 2. Cromatograma de una muestra de pisco proveniente de un vino base con borras con 150 días de reposo.

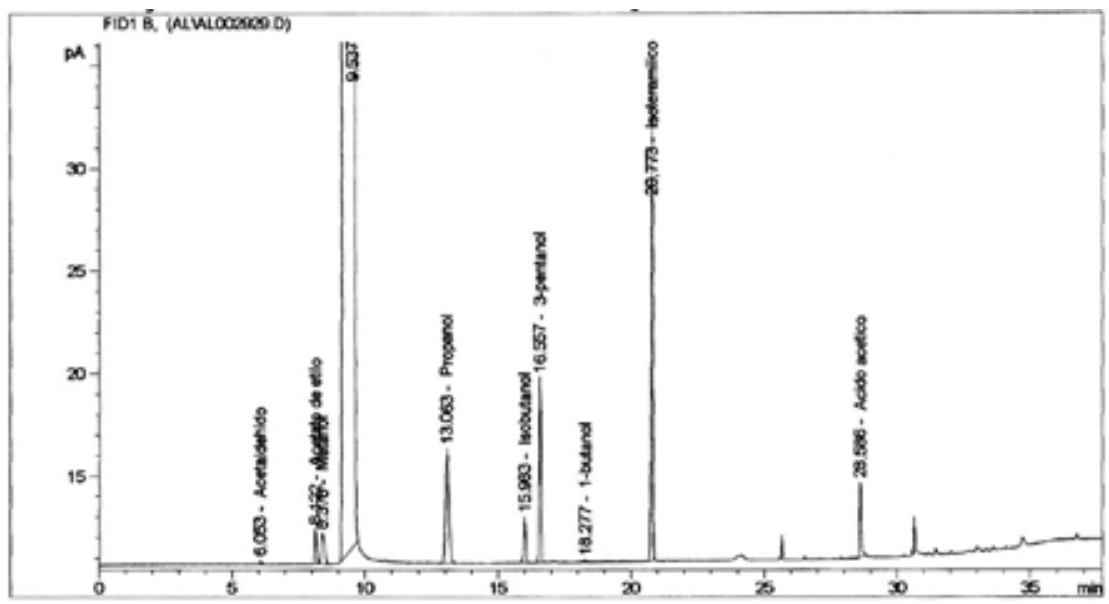

Figura 3. Cromatograma de una muestra de pisco proveniente de un vino base sin borras con 150 días de reposo. 
Una fermentación maloláctica normal pura aumenta la acidez volátil entre 0,05 a $0,15 \mathrm{~g} / \mathrm{L}$, aproximadamente ${ }^{3}$. En esta investigación, el aumento de la acidez volátil en los vinos base con borras fue de más de 1,00 g/L. En efecto, luego de 150 días de reposo y con una fermentación maloláctica concluida muchas semanas atrás, se habría desencadenado una descontrolada producción de ácido acético a partir del ácido cítrico remanente. Según Hidalgo ${ }^{4}$, la duración de la fermentación maloláctica transcurre generalmente en un plazo de una a dos semanas.

Generalmente, el ácido tartárico no es metabolizado por las bacterias lácticas, aunque en ocasiones y después de haber sido degradados los ácidos málico y cítrico, puede ser atacado por determinados Lactobacillus $^{4}$. Esta alteración lleva primero a la transformación del ácido tartárico en ácido láctico y en ácido acético; y segundo a la producción de ácido acético y ácido succínico ${ }^{14}$. Es muy probable que durante los 150 días de reposo, también se haya degradado en su totalidad el ácido cítrico, siendo el ácido tartárico el siguiente sustrato a utilizar por las bacterias lácticas.

Esta alteración es propia de vinos de zonas cálidas, donde su pH es elevado con valores entre 3,6 a 3,9 y con niveles de anhídrido sulfuroso bajos, que permiten un fácil desarrollo de los bacilos frente a los $\operatorname{cocos}^{4}$. En efecto, los valores de $\mathrm{pH}$ durante el tiempo de reposo de los vinos base con borras tuvieron un promedio de 4,23. Además, debido a que estos vinos base eran destinados a destilarse, no se utilizó anhídrido sulfuroso; presentándose así las condiciones propicias para esta alteración.

De acuerdo a los resultados estadísticos, habría que considerar que los piscos provenientes de vinos base con borras con 60 o más días de reposo, y los provenientes de vinos base sin borras con 150 o más días de reposo, serán siempre significativamente mayores en cuanto al contenido de ácido acético que los provenientes de vinos base con 0 días de reposo (figura 1).

En la figura 1 se observa claramente una mayor concentración de ácido acético en las muestras de pisco provenientes de vinos base con borras en comparación con los provenientes de vinos base sin borras, a los 60 y 150 días de reposo.

Efectivamente, en los vinos base sin borras no se habría desencadenado la fermentación maloláctica. Según Suárez e Iñigo ${ }^{16}$, la posibilidad de degradación del ácido málico disminuye, ya que él descube rápido y el trasiego precoz, alejan las bacterias demasiado pronto, además de empobrecer el medio en vitaminas y sustancias nitrogenadas que proceden de la autolisis de las levaduras. Las clarificaciones tempranas, habituales en vinos para la adquisición del grado de limpidez necesario, al igual que las filtraciones, tienden a retardar o incluso inhibir la fermentación maloláctica ${ }^{16}$.

Por lo tanto, el leve incremento de ácido acético observado en los piscos provenientes de vinos base sin borras, podría haber sido a causa de la hidrólisis de algunos ésteres acéticos. Según Flanzy ${ }^{5}$, la composición de los ésteres durante la conservación del vino sufre un reajuste (hidrólisis/esterificación) muy lento, debido a que tienen lugar unas reacciones puramente químicas entre los reactivos (éster, agua, alcohol, ácido), hasta que se alcanza un estado 
de equilibrio. Sin embargo, no se descarta un desencadenamiento tardío de la fermentación maloláctica.

En los piscos provenientes de vinos base con borras con 150 días de reposo, se obtuvo un contenido promedio de $0,69 \mathrm{~g} / \mathrm{L}$ de ácido acético, ligeramente por debajo del máximo permitido por el Reglamento de la Denominación de Origen PISCO (200 mg/100 ml A.A. $)^{1}$ o un equivalente a $0,76 \mathrm{~g} / \mathrm{L}$; pero por encima del umbral de detección olfativa del ácido acético en el pisco, según Cacho et al. ${ }^{17}$, que es $0,6 \mathrm{~g} / \mathrm{L}$ o $150 \mathrm{mg} / 100 \mathrm{ml}$ A.A.

Aunque es necesario una pequeña cantidad de ácido acético para que los aguardientes adquieran cuerpo, importante para la calidad, un exceso de éste genera un alto contenido de acetato de etilo que desmejora la calidad del producto ${ }^{7}$. Es así que, el ácido acético de piscos provenientes de vinos base que reposaron con sus borras, podrían influir negativamente en la calidad del producto final.

\section{Propanol}

Tal como se observa en la figura 4, el contenido de propanol tuvo mayores concentraciones en los piscos provenientes de vinos base con borras con 60 y 150 días de reposo, mientras que para los provenientes de vinos base sin borras no hubo variación durante todo el tiempo de reposo.

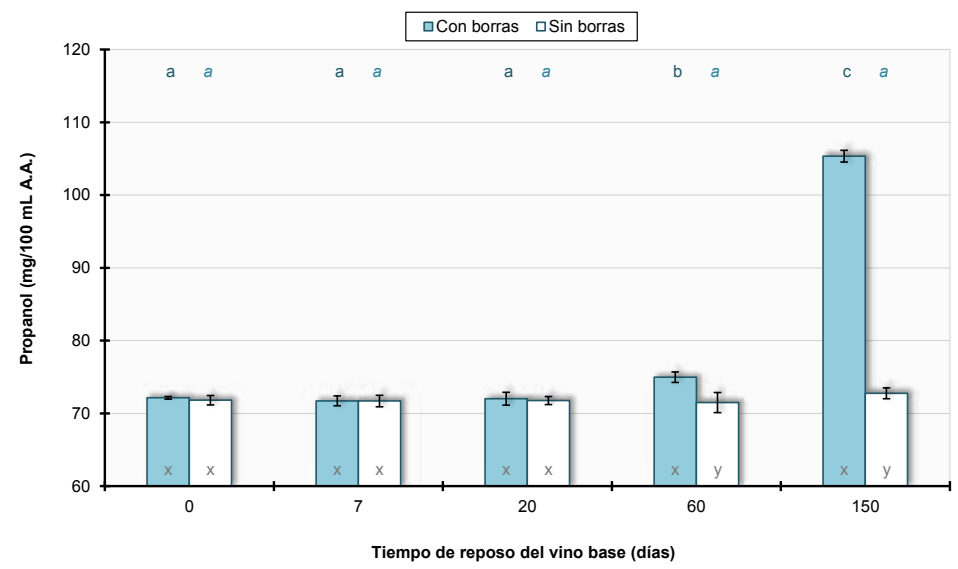

Figura 4. Contenido de propanol en los piscos provenientes de vinos base (con y sin borras) con diferentes tiempos de reposo.

Se ha mencionado que el tenor en alcoholes superiores del vino puede aumentar debido a alteraciones microbianas causadas por levaduras o por bacterias ${ }^{15}$. Así, durante la fermentación maloláctica, aumenta el contenido de propanol, el butanol-2 y el hexano ${ }^{16}$. Esto sustenta lo antes discutido sobre la ocurrencia de la fermentación maloláctica en los vinos base con borras durante el tiempo de reposo. 
De acuerdo a los resultados estadísticos, habría que considerar que los piscos provenientes de vinos base con borras con 60 o más días de reposo serán siempre significativamente mayores en cuanto al contenido de propanol que los provenientes de vinos base con 0 días de reposo (figura 4).

En la figura 4 se observa claramente una mayor concentración de propanol en las muestras de pisco provenientes de vinos base con borras en comparación con los provenientes de vinos base sin borras, a los 60 y 150 días de reposo.

En efecto, para los piscos provenientes de vinos base sin borras no hubo variación en el contenido de propanol a lo largo de todo el tiempo de reposo. Esto debido a que no se habría realizado la fermentación maloláctica. Según Suárez e Iñigo ${ }^{16}$, las clarificaciones tempranas, habituales en vinos para la adquisición del grado de limpidez necesario, al igual que las filtraciones, tienden a retardar o incluso inhibir la fermentación maloláctica.

De acuerdo con el Reglamento de la Denominación de Origen PISCO ${ }^{1}$, el propanol, entre otros alcoholes superiores, debe estar presente sin precisar exigencias de máximos y mínimos. Sin embargo, los contenidos promedio de propanol de los piscos en esta segunda etapa de la investigación, en especial los provenientes de vinos base con borras con 150 días de reposo (105.34 mg/100 mL A.A.), presentaron valores bastante altos.

El propanol y butanol, a concentraciones normales, son inodoros pero contribuyen a las características del alcohol mismo ${ }^{7}$. Es así, que concentraciones elevadas de propanol como las que se detectaron en el presente estudio, podrían influir significativamente en las características sensoriales finales de los piscos.

\section{Acetato de etilo}

Tal como se observa en la figura 5, el contenido de acetato de etilo tuvo mayores concentraciones en los piscos provenientes de vinos base con borras con 150 días de reposo; mientras que para los provenientes de vinos base sin borras hubo un leve incremento de acetato de etilo cuando los vinos base pasaron de un tiempo de reposo de 0 a 7 días, y una disminución cuando pasaron de un tiempo de reposo de 60 a 150 días.

Se ha mencionado que durante la fermentación maloláctica, se forman ésteres como el acetato de etilo de olor a pegamento o el lactato de etilo de olor lácteo ${ }^{4}$, lo que coincide con los resultados obtenidos para los piscos provenientes de vinos base con borras.

El incremento de acetato de etilo en los piscos provenientes de vinos base con borras, estaría relacionado con el incremento de uno de sus sustratos, el ácido acético. El incremento de éste se hizo considerable a partir del día 60 del tiempo de reposo (figura 1), mientras que para el acetato de etilo, se hizo considerable a partir del día 150 (figura 5). En efecto, una esterificación química requiere primero la existencia de los sustratos. 
De acuerdo a los resultados estadísticos, habría que considerar que los piscos provenientes de vinos base con borras con 150 o más días de reposo, serán siempre significativamente mayores en cuanto al contenido de acetato de etilo que los provenientes de vinos base con 0 días de reposo (figura 5).

El incremento de acetato de etilo en los piscos provenientes de vinos base sin borras desde los 0 a 7 días de reposo, y el posterior descenso hacia al final del mismo, habrían sido a causa de los procesos de esterificación e hidrólisis, respectivamente. Según Flanzy ${ }^{5}$, la composición de los ésteres durante la conservación del vino sufre un reajuste (hidrólisis/esterificación) muy lento, debido a que tienen lugar unas reacciones puramente químicas entre los reactivos (éster, agua, alcohol, ácido), hasta que se alcanza un estado de equilibrio.

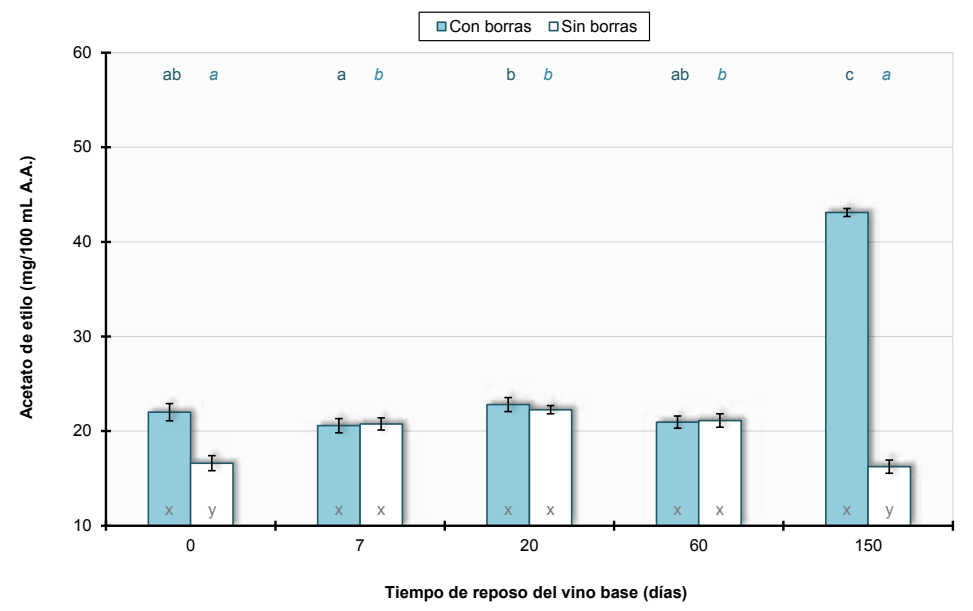

Figura 5. Contenido de acetato de etilo en los piscos provenientes de vinos base (con y sin borras) con diferentes tiempos de reposo.

La destilación favorece el enriquecimiento en ésteres volátiles tales como el acetato de etilo. Algunos ésteres se forman en los alambiques por las altas temperaturas provocándose una esterificación con los ácidos grasos liberados desde las células de las levaduras ${ }^{7}$. Esto coincide con el hecho de que el contenido de acetato de etilo en los piscos provenientes de vinos base con borras haya sido significativamente mayor en comparación con los provenientes de vinos base sin borras, a los 0 días de reposo (figura 5); lo que indica que este tipo de éster se encuentran en regular cantidad dentro de la célula de levadura al final de la fermentación.

Los contenidos promedio de acetato de etilo de los piscos en esta segunda etapa de la investigación, se encontraron entre el mínimo y el máximo permitido por el Reglamento de la Denominación de Origen PISCO (10,0 a 280,0 mg/100 mL A.A.) ${ }^{1}$.

Aunque el acetato de etilo, cuantitativamente importante en el pisco, es considerado un componente negativo a la calidad por ser el responsable del olor a picado7, las concentraciones 
encontradas en la mayoría de los piscos están por debajo del nivel de percepción ${ }^{10}$. Sin embargo, de acuerdo con Ribéreau-Gayon et al. ${ }^{15}$, el umbral de detección del acetato de etilo es cercano a $16 \mathrm{mg} / 100 \mathrm{~mL}$ A.A., por lo que en este caso, casi todos los valores obtenidos durante esta etapa, sí afectarían negativamente el sabor y el olor del producto final.

\section{Acetato de iso-amilo}

Tal como se observa en la figura 6 , el contenido de acetato de iso-amilo tuvo un incremento cuando los vinos base con y sin borras pasaron de un tiempo de reposo de 0 a 7 días, y una disminución cuando pasaron de un tiempo de reposo de 20 a 60 días. El acetato de iso-amilo tuvo mayores concentraciones en los piscos provenientes de vinos base con borras con 150 días de reposo.

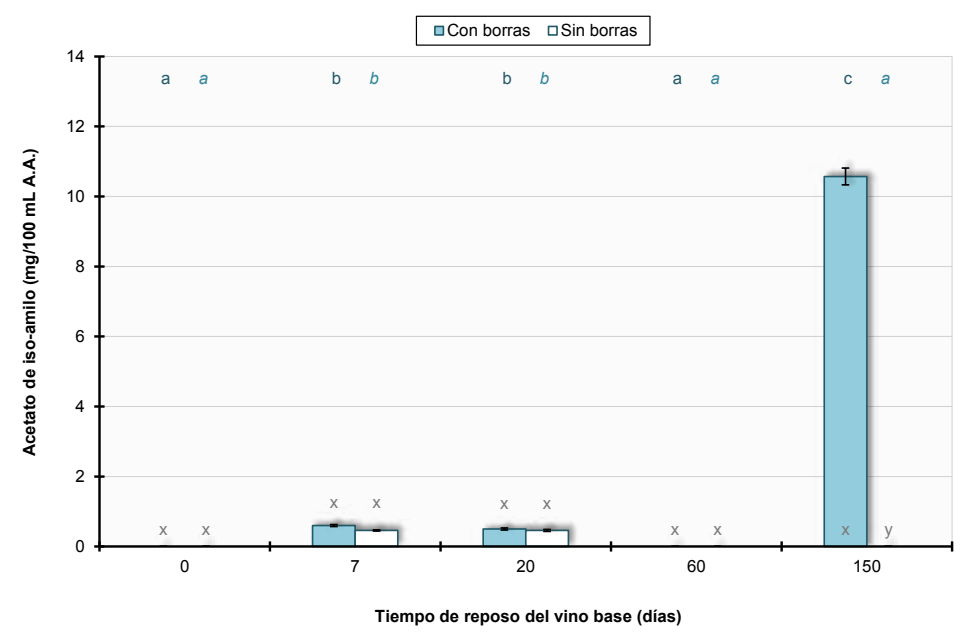

Figura 6. Contenido de acetato de iso-amilo en los piscos provenientes de vinos base (con y sin borras) con diferentes tiempos de reposo.

Desde el día 20 al día 60 del reposo, se observa la desaparición total de las pequeñas cantidades de acetato de iso-amilo en los piscos provenientes de vinos base con y sin borras producidas anteriormente (figura 6), debido a la incidencia de la fermentación maloláctica. Según Rankine ${ }^{9}$, durante esta fermentación puede tener lugar una reducción considerable de ciertos ésteres con olor a fruta, como el acetato de isoamilo, que desaparece en un $80 \%$ a lo largo de esta transformación.

Sin embargo, al final del tiempo de reposo, la concentración de acetato de iso-amilo se incrementa de manera sustancial. Este incremento de acetato de iso-amilo en los piscos provenientes de vinos base con borras, estaría relacionado con el incremento de uno de sus sustratos, el ácido acético. El incremento de éste se hizo considerable a partir del día 60 del tiempo de reposo (figura 1), mientras que para el acetato de etilo se hizo considerable a partir 
del día 150 (figura 6). En efecto, una esterificación química requiere primero la existencia de los sustratos.

De acuerdo a los resultados estadísticos, habría que considerar que los piscos provenientes de vinos base con borras con 150 o más días de reposo, serán siempre significativamente mayores en cuanto al contenido de acetato de iso-amilo que los provenientes de vinos base con 0 días de reposo (figura 6).

De acuerdo con el Reglamento de la Denominación de Origen PISCO $^{1}$, se menciona que es posible que el acetato de iso-amilo no esté presente, lo cual coincide con los resultados obtenidos con respecto a los piscos provenientes de vinos base con 0 días de reposo. Se menciona también que de estar presente el acetato de iso-amilo, la suma con el acetato de etilo no debe sobrepasar de $330 \mathrm{mg} / 100 \mathrm{~mL}$ A.A. ${ }^{1}$, lo cual también coincide con los resultados obtenidos.

\section{Acetaldehído}

Tal como se observa en la figura 7, el contenido de acetaldehído tuvo menores concentraciones en los piscos provenientes de vinos base con borras con mayores tiempos de reposo; mientras que para los provenientes de vinos base sin borras hubo un incremento de acetaldehído cuando los vinos base pasaron de un tiempo de reposo de 7 a 20 días, y una disminución importante cuando pasaron de un tiempo de reposo de 60 a 150 días.

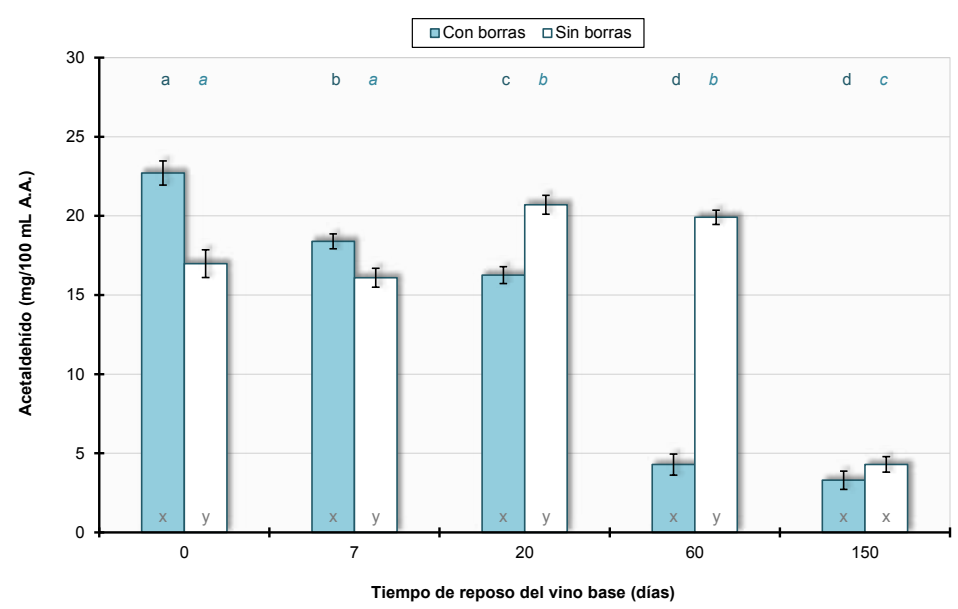

Figura 6. Contenido de acetaldehído en los piscos provenientes de vinos base (con y sin borras) con diferentes tiempos de reposo. 
Se ha demostrado que la fermentación maloláctica llevada a cabo con Oenococcus oeni es un mecanismo regulador del contenido de los vinos en acetaldehído: cantidades importantes de este compuesto desaparecen en el transcurso de la degradación maloláctica ${ }^{5}$. En efecto, los piscos provenientes de vinos base con borras (lo que aseguró la presencia de bacterias lácticas), presentaron una disminución importante y sostenida de acetaldehído durante los primeros 60 días del reposo.

El contenido de acetaldehído en los piscos provenientes de vinos base con borras fue significativamente mayor en comparación con los provenientes de vinos base sin borras, a los 0 días de reposo (figura 7); lo que indica que este tipo de aldehído se encuentran en regular cantidad dentro de la célula de levadura al final de la fermentación.

Generalmente, hay una formación de acetaldehído bastante rápida en las primeras semanas, seguida de un período en que la concentración permanece estacionaria o se reduce, y de otro en que se vuelve a elevar o continúa cayendo. Todo depende de las condiciones de acceso al aire ${ }^{18}$. Una oxidación posterior del acetaldehído, con formación de pequeñas cantidades de ácido acético, y la interacción con el etanol para producir acetal, serían las causas de su detrimento $^{19}$. Estas afirmaciones coinciden con el comportamiento mostrado por los piscos provenientes de vinos base sin borras.

De acuerdo a los resultados estadísticos, habría que considerar que los piscos provenientes de vinos base con borras hasta con 60 días de reposo, serán siempre significativamente menores en cuanto al contenido de acetaldehído que los provenientes de vinos base con 0 días de reposo (figura 7).

\section{CONCLUSIONES}

Los piscos provenientes de vinos base con mayores tiempos de reposo presentan mayores contenidos de ácido acético (con borras: desde $0,15 \mathrm{~g} / \mathrm{L}$ con 0 días de reposo hasta $0,30 \mathrm{~g} / \mathrm{L}$ con 60 días de reposo y $0,69 \mathrm{~g} / \mathrm{L}$ con 150 días de reposo; sin borras: desde $0,14 \mathrm{~g} / \mathrm{L}$ con 0 días de reposo hasta $0,26 \mathrm{~g} / \mathrm{L}$ con 150 días de reposo), propanol (con borras: desde 72,15 mg/100 $\mathrm{mL}$ A.A. con 0 días de reposo hasta 105,34 mg/100 mL A.A. con 150 días de reposo), acetato de etilo (con borras: desde 22,00 mg/100 mL A.A. con 0 días de reposo hasta 43,10 mg/100 $\mathrm{mL}$ A.A. con 150 días de reposo) y acetato de iso-amilo (con borras: desde $0,00 \mathrm{mg} / 100 \mathrm{~mL}$ A.A. con 0 días de reposo hasta $10,57 \mathrm{mg} / 100 \mathrm{~mL}$ A.A. con 150 días de reposo); y menores contenidos de acetaldehído (con borras: desde $22,71 \mathrm{mg} / 100 \mathrm{~mL}$ A.A. con 0 días de reposo hasta 4,29 mg/100 mL A.A. con 60 días de reposo y 3,30 mg/100 mL A.A. con 150 días de reposo; sin borras: desde 16,98 mg/100 $\mathrm{mL}$ A.A. con 0 días de reposo hasta 4,30 mg/100 mL A.A. con 150 días de reposo). Los piscos destilados de vinos base con borras presentan mayores cantidades de acetato de etilo (22,00 vs. $16,61 \mathrm{mg} / 100 \mathrm{~mL}$ A.A.) y acetaldehído (22,71 vs. $16,98 \mathrm{mg} / 100 \mathrm{~mL}$ A.A.), que sus destilados de vinos base sin borras, con 0 días de reposo. 


\section{AGRADECIMIENTO}

A "Bodegas \& Viñedos Tabernero S.A.C." por las instalaciones, materia prima, insumos, equipos y materiales. A "La Molina Calidad Total Laboratorios" por los análisis de cromatografía de gases.

\section{REFERENCIAS BIBLIOGRÁFICAS}

1. Asociación Nacional de Productores de Pisco. Reglamento de la Denominación de Origen Pisco. Lima: INDECOPI; 2011.

2. Girard G. Bases científicas y tecnológicas de la enología. 1era. edición. Zaragoza: Editorial Acribia S.A.; 2004.

3. Blouin J, Peynaud É. Enología práctica: conocimiento y elaboración del vino. 4ta. edición. Madrid: Ediciones Mundi-Prensa; 2004.

4. Hidalgo J. Tratado de enología; tomos I y II. 2da. edición. Madrid: Ediciones MundiPrensa; 2011.

5. Flanzy C. Enología: fundamentos científicos y tecnológicos. 1era. edición. Madrid: Vicente Ediciones y Ediciones Mundi-Prensa; 2000.

6. Domenech A. Influencia de la maceración con orujos y corte de cabeza en el contenido de terpenos en piscos de la variedad Italia (Vitis vinífera L. var. Italia). [Tesis de pregrado]. Lima: Universidad Nacional Agraria La Molina; 2006.

7. Hatta B. Influencia de la fermentación con orujos en los componentes volátiles del pisco de uva Italia (Vitis vinifera L. var. Italia). [Tesis de maestría]. Lima: Universidad Nacional Agraria La Molina; 2004.

8. Larrea A. Enología básica: fundamentos de vinificación. 1era. edición. Barcelona: Editorial Aedos-Barcelona; 1983.

9. Rankine B. Manual práctico de enología. 3era. edición. Zaragoza: Editorial Acribia S.A.; 2000.

10. Léauté R. Distillation in alambic. Am J Enol Viticult. 1990; 41: 90-103.

11. Miličevič B, Banović M, Kovačevič K, Gracin, L. Impact of grape varieties on wine distillates flavour. Food Technol. Biotech. 2002; 40: 227-232.

12. INDECOPI. Norma Técnica Peruana: Bebidas alcohólicas. Método de ensayo. Determinación de metanol y de congéneres en bebidas alcohólicas y alcohol etílico empleado en su elaboración, mediante cromatografía de gases. NTP 211.035: 2008. Lima: INDECOPI; 2008.

13. Asencios E. Influencia de la fermentación con levaduras nativas y comerciales en las características del pisco de Uvina o Jacquez (Vitis aestivalis-cinerea x Vitis vinífera) del valle de Lunahuaná. [Tesis de pregrado]. Lima: Universidad Nacional Agraria La Molina; 2007.

14. Usseglio-Tomasset L. Química enológica. 4ta. edición. Madrid: Ediciones MundiPrensa; 1998.

15. Ribéreau-Gayon P, Glories Y, Maujean A, Dubourdieu D. Tratado de enología: química del vino. 1era edición. Buenos Aires: Editorial Hemisferio Sur S.A.; 2003. 
16. Suárez JA, Íñigo B. Microbiología enológica: fundamentos de vinificación. 1era. edición. Madrid: Ediciones Mundi-Prensa; 1990.

17. Cacho JF, Moncayo L, Palma JC, Ferreira V, Culleré L. Characterization of the aromatic profile of the Italia variety of peruvian Pisco by gas chromatography-olfactometry and gas chromatography coupled with flame ionization and mass spectrometry detection systems. Food Res Int. 2012; 49: 117-125.

18. Suárez JA. Levaduras vínicas: funcionalidad y uso en bodegas. 1era. edición. Madrid: Ediciones Mundi-Prensa; 1997.

19. Christopoulou-Gerogiannaki M, Gerogiannaki L, Anagnostartas E, Stavrakas DE, Pilissiou M. Identification of volatile compounds in Hellenic alcoholic beverages from native white grape varieties (Vítis vinifera L.). J Food Technol. 2007; 5: 233-241. 